\title{
Monitoramento hormonal não invasivo em aves - uma revisão
}

Non-invasive hormonal monitoring in birds - a review

$$
\text { Bruna Todeschini Vieira }{ }^{1} \text {, Nei Moreira }{ }^{1}
$$

Universidade Federal do Paraná, Programa de Pós-Graduação em Zoologia, PR, Brasil

${ }^{1}$ Correspondência para Av. Cel. Francisco H. dos Santos, 100 - Jardim das Américas, Curitiba - PR

\section{Resumo}

Para espécies silvestres, a coleta de amostras para monitorar o estresse e a função reprodutiva sempre foi um desafio. Coletas de sangue em animais silvestres são difíceis de serem realizadas, pois sempre exige a contenção física do animal, seguida ou não de sedação ou anestesia, que acaba dificultando ou impossibilitando coletas muito frequentes, tanto pelo estresse que causa ao animal como pelos cuidados clínicos que se dever ter no uso dessas drogas. As técnicas de dosagens hormonais não invasivas vieram como uma boa opção, realizando a análise destes hormônios ou seus metabólitos. Estes são excretados nas fezes, urina, excretas, pele, pelos ou saliva, permitindo o acompanhamento por longos períodos, pois em muitos casos, não exigem manipular o animal. As amostras mais utilizadas são fezes e urina e, no caso das aves, excretas. As técnicas mais utilizadas são os ensaios imunológicos, utilizado isótopos radioativos (radioimunoensaio) ou enzimas (enzimoimunoensaio). Nesta revisão, são apresentadas as principais vantagens da dosagem não invasiva, focando principalmente seu uso em aves, utilizando excretas e abordando também as principais técnicas de dosagem.

Palavras-chave: Endocrinologia, excretas, radioimunoensaio, enzimoimunoensaio.

\begin{abstract}
For wild species, sampling for monitoring stress and reproductive function has always been a challenge. Blood collections in wild animals are difficult to perform because they often require physical restraint of the animal, which causes stress, or at least sedation or anesthesia, which makes it difficult or impossible for frequent collections. Noninvasive hormone monitoring techniques came as a good option, performing analysis of these hormones or their metabolites. These are excreted in feces, urine, excreta, hair or saliva, allowing the collection for long periods, since in many cases they do not require to manipulate the animal. The most commonly used samples are feces and urine, and in the case of birds, excreta. The most commonly used techniques are immunological assays, radioactive isotopes (radioimmunoassay) or enzymes (enzymeimmunoassay). In this review, the main advantages of noninvasive hormonal monitoring are presented, focusing more on their use in birds, using excreta and also addressing the main dosage techniques.
\end{abstract}

Keywords: endocrinology, excreta, radioimmunoassay, enzymeimmunoassay.

\section{Introdução}

Análises hormonais são consideradas métodos precisos para monitorar a função reprodutiva e o estresse em várias espécies, mas exigem um conhecimento básico da fisiologia da espécie em estudo, como o metabolismo hormonal e as formas de secreção e excreção (Hodges et al, 2010), principalmente quando a dosagem é feita utilizando-se metabólitos hormonais.

Alguns dos problemas enfrentados na análise hormonal em soro ou plasma, que exige a coleta de sangue, envolvem, no caso de animais de vida livre, a logística para se fazer as coletas, além da quantidade de sangue para realizar o ensaio. Em passeriformes, por exemplo, a quantidade que pode ser coletada de sangue é muito pequena, proporcional ao pequeno tamanho. E como a amostra sanguínea representa um valor pontual de determinado hormônio - como estava naquele momento da coleta - pode ser que uma única coleta apenas, não seja suficiente. Ao contrário, nas fezes, obtemos um pool dos hormônios excretados, o que pode melhor representar os resultados (Goymann, 2005).

As dosagens hormonais, podem ser realizadas, em geral, a partir de várias amostras biológicas, como: urina, saliva, soro, sangue, pelos e fezes, sendo que em urina e fezes os protocolos já estão bem estabelecidos para o monitoramento de esteroides em várias espécies (Brown, 2008). 
Nas aves, o termo excreta é utilizado, pois não há separação entre fezes e urina. As coletas não interferem muito no comportamento normal do animal, permitindo que sejam realizadas várias coletas do mesmo indivíduo (Goymann, 2005). A vantagem de utilizar as excretas para dosar hormônios é determinar a função gonadal sem precisar tocar o animal, pois a amostra pode ser coletada no chão do recinto e levada ao laboratório (Pukazhenthi e Wildt, 2004).

\section{Amostragem não invasiva}

As técnicas de monitoramento hormonal não invasivo devem ser estudadas com atenção, pois diminuem os riscos para o animal e para a coleta, sem interferir com o comportamento natural (Buchanan e Goldsmith, 2004; Goymann, 2012). Além disso, permitem a visualização de um panorama de hormônios (e até outros metabólitos) sem causar estresse, apresentando um resultado fiel (Palme, 2005; Schwarzenberger, 2007; Goymann, 2012; Wasser et al., 2000). Seria importante você acrescentar uma referência destacando as condições das excretas no momento das coletas (fezes frescas, por exemplo)

As primeiras informações obtidas nas análises hormonais foram de espécies de mamíferos domésticos, e ajudaram a delinear: Função gonadal com base no sexo, idade; sazonalidade; tempo da espermatogênese e ovulação; tipo de ovulação (espontânea ou induzida); formas de superar a infertilidade; definir protocolos de reprodução assistida (Pukazhenthi e Wildt, 2004).

Com os avanços da qualidade dos protocolos e procedimentos para a anestesia em animais silvestres, especialmente mamíferos, em meados dos anos setenta, amostras sanguíneas começaram a ser coletadas, porém não poderiam ser realizadas com frequência, inviabilizando as coletas sequenciais por longos períodos. Junto com isso, algumas evidências de alterações hormonais causadas pela anestesia começaram a surgir, fazendo-se necessária a busca por alternativas que apresentassem resultados mais precisos (Pukazhenthi e Wildt, 2004).

Sobre o estresse, de acordo com o trabalho desenvolvido por Gratto-Trevor e colaboradores, em 1991, é necessário levar em conta que a captura, o manejo do animal e a coleta em si podem causar um episódio de estresse, levando a alterações dos valores reais dos hormônios circulantes, a exemplo do que se observa em estudos com cortisol e testosterona, entre outros. No experimento, trabalharam com a ave pilrito-semipalmado, também conhecido como "maçariquinho" (Calidris pusilla), realizaram uma coleta de sangue assim que as aves foram capturadas e outra 15 minutos depois, para verificar o efeito nos hormônios. Os resultados obtidos mostraram, na segunda coleta, um aumento da corticosterona em todos os animais, já outros hormônios, como testosterona e prolactina, não seguiram um padrão, mas os níveis foram menores na maioria dos animais, em relação à primeira coleta.

Apesar de parecerem ótimas opções, as desvantagens das coletas não invasivas devem ser consideradas, principalmente quando envolve animais em um ambiente não controlado (Goymann, 2012). Visto que, quando a análise é feita em soro ou plasma, o que está sendo mensurado é a molécula do hormônio em si, quando utiliza outras amostras biológicas como fezes, urina ou excretas, o que é medido é o produto final do metabolismo, que pode ser modificado intensamente pelos processos naturais, como as bactérias intestinais (Taylor, 1971; Goymann, 2005; Klasing, 2005; Palme, 2005). Dependendo da espécie, esses metabólitos podem ser excretados em maior quantidade na urina ou nas fezes (Pukazhenthi e Wildt, 2004).

De acordo com revisões relatadas por Palme (2005) e Goymann (2012), existem diferenças em vários aspectos quanto à excreção dos hormônios nas fezes. Goymann (2012) trouxe um compilado de trabalhos nos quais há registros de diferenças na excreção entre fêmeas e machos, como o do próprio Goymann (2005) no qual, trabalhando com o cartaxo-comum (Saxicola rubicola), um pequeno passeriforme, percebeu que os machos e fêmeas metabolizam a testosterona de formas diferentes, e que a mensuração desse hormônio com o anticorpo que é ótimo para aferir o metabólito de testosterona das excretas dos machos, não é ideal para fêmeas dessa espécie. As revisões, também fazem referências a possíveis diferenças ligadas à dieta, à taxa metabólica, quantidade de alimentação ingerida e degradação bacteriana.

O que devemos considerar é que não se pode generalizar um ensaio para todas as espécies, as validações - que ainda serão abordadas - se fazem sempre necessárias. A influência de algumas variáveis, citadas anteriormente, pode ser diminuída quando se trabalha com uma população controlada, de cativeiro.

\section{Amostras}

A escolha da amostra que será utilizada deve ser feita levando em conta: a informação que está se buscando; o ensaio que será utilizado; a particularidade da espécie quanto à excreção dos metabólitos; e a logística mais fácil para a realização da coleta, principalmente quando há exigência de coletas durante longo período (Heistermann, 2010; Hodges et al., 2010). 
No trabalho realizado em corujas por Wasser e Hunt (2005), os autores consideraram que o tempo curto entre a secreção e a excreção dos hormônios nas aves, e as excretas serem pouco volumosas, são vantagens para diminuir interferências do metabolismo sobre as amostras. No trabalho foram realizados ensaios utilizando a administração intramuscular de hormônios radiomarcados nos animais, e a coleta de excretas foi realizada em um intervalo constante. Encontraram resultados para todas as espécies de corujas que trabalharam, e para os hormônios testados - glicocorticoides e esteroides sexuais - o tempo para aparecimento nas excretas (lag time) foi de uma a quatro horas.

Urina

O uso da urina como amostra biológica para ensaios hormonais iniciou nos anos 80, junto com o aumento da demanda por mais pesquisa científica dentro da gestão de zoológicos. Foi considerada a alternativa mais prática quando comparada à coleta sanguínea e ampliou muito os dados de reprodução e estresse em várias espécies (Hodges, 2010).

Como existem diferenças na concentração da urina entre espécies e indivíduos, é necessário determinar o quão diluído ou concentrada a amostra encontra-se. Para isso é utilizada a mensuração da creatinina, a qual apresenta uma taxa de excreção que correlaciona bem com a taxa dos hormônios. E, dependendo da taxa de depuração renal ou clearance renal, o resultado da dosagem pode refletir a um evento de algumas horas antes da coleta (Hodges, 2010). O clearance renal é a taxa em que uma certa substância é retirada do plasma, quando filtrado pelo rim (Cunningham e Klein, 2007).

Na urina, os hormônios apresentam-se da forma conjugada, como sulfato ou glicuronídeo (Möstl, Rettenbacher e Palme, 2005), e utilizando o ensaio correto, é possível analisar diretamente os conjugados de esteroides, sem a necessidade de extração por algum solvente. O uso da urina como amostra biológica é maior quando se procura hormônios esteroides, porém, há excreção urinária de hormônios peptídicos (formados por resíduos de aminoácidos - hormônio luteinizante, hormônio folículo estimulante e gonadotrofinas coriônicas), que também podem ser dosados (Hodges et al., 2010).

Fezes

Os metabólitos de hormônios que são excretados nas fezes refletem os padrões sanguíneos, respeitando a taxa de metabolização e de passagem (Pukazhenthi e Wildt, 2004). A taxa de passagem é o tempo em que o que o conteúdo ingerido pelo animal demora para ser excretado. Em galinhas, utilizando marcadores insolúveis (óxido de cromo, p. ex.), a taxa de passagem foi 1,6 a 2,6 horas depois da ingestão. Este tempo deve ser considerado uma média, visto que vários fatores podem alterar, inclusive a quantidade de proteína e gordura da dieta (Scanes, 2015).

Dada as diferenças existentes no metabolismo de esteroides entre as espécies e até entre espécies próximas, é muito importante a validação cuidadosa dos métodos de ensaio, para se chegar a resultados precisos e significativos, conforme relata Schwarzenberger (2007). Neste sentido, animais que estão em cativeiro são ótimos para serem estudados, visto que as coletas podem ser realizadas com maior frequência, e os estudos ligando endocrinologia, fisiologia, reprodução e estresse, relacionados com fatores ambientais e sociais podem ser executados e analisados para estabelecer como estes impactam na saúde do animal (Schwarzenberger, 2007).

No trabalho com gaviões-reais (Harpia harpyja) de Blank e Moreira (2015), foram obtidos bons resultados utilizando excretas para detecção de metabólitos de andrógenos. Em 2015, Ferreira e colaboradores conseguiram resultados satisfatórios analisando metabólitos de glicocorticoides em excretas de papagaio-verdadeiro (Amazona aestiva), bem como o trabalho relacionando o estresse e enriquecimento ambiental em araras-canindé (Ara ararauna) de Almeida et al. (2016). Os resultados alcançados nos levam a acreditar que as técnicas são adequadas para utilizar em aves, quando feita a validação apropriada.

\section{Validações}

Os hormônios, em geral, apresentam vários metabólitos na excreta, e nem todos são conhecidos. Os ensaios utilizados são desenvolvidos para a detecção dos hormônios, em sua forma ativa, e não para metabólitos. Porém, com o crescimento da necessidade das análises hormonais em animais, começou-se a testar a utilização destes ensaios para detecção de produtos do metabolismo dos hormônios. Este passo é importantíssimo, pois a excreção de diferentes metabólitos pode não ser a mesma entre as espécies ou até 
entre os sexos, ou seja, um método que funciona para uma espécie não necessariamente deve funcionar para outra, mesmo que sejam espécies próximas (Goymann, 2005).

Quando amostras como o sangue são utilizadas, os hormônios estão presentes em maior quantidade em sua forma biologicamente ativa, portanto as reações cruzadas com estruturas similares não são consideradas relevantes. Quando trabalhamos com metabólitos, existem outras infinitas substâncias nas excretas, urina ou fezes, além dos metabólitos hormonais. Caso o anticorpo não tenha reações cruzadas com outras substâncias, não é um grande problema. Porém, deve-se ter certeza de que o anticorpo está reagindo, pelo menos em maioria, com metabólitos dos hormônios procurados, e não com substâncias com estruturas similares, mas funcionalmente diferentes dos hormônios. Portanto, para utilizar análises de metabólitos, validações devem ser cuidadosamente realizadas, para assegurar que o ensaio detectará substâncias relevantes (Goymann, 2012) e que realmente reflita os eventos fisiológicos interessantes (Brown, 2008), de maneira a garantir ao pesquisador esteja efetivamente, mensurando o hormônio de interesse.

Uma das formas mais comuns e baratas de dosagem hormonal é por ensaios enzimáticos (enzimoimunoensaio) ou utilizando isótopos radioativos (radioimunoensaio). A reação é baseada em uma ligação entre antígeno e anticorpo. No caso, o hormônio que está na amostra é o antígeno, e este vai se ligar a um anticorpo específico contra ele. Este anticorpo é marcado radioativamente ou com enzimas, que vão gerar reações colorimétricas com o seu substrato. Ambas as técnicas utilizam um anticorpo que reage contra o hormônio que está sendo procurado ou reage com moléculas resultantes do metabolismo destes hormônios, e que são excretadas nas fezes e/ou urina dos animais (Goymann, 2012).

\section{Técnicas para validação}

Existem técnicas que podem ser utilizadas para a validação do ensaio para um hormônio específico. Segundo o Manual de Endocrinologia do Instituto Smithsoniano de Conservação Biológica (SCBI) (Brown, 2008), as validações são essenciais para demonstrar se a dosagem hormonal está realmente refletindo o evento fisiológico que estar se buscando.

A validação pode ser realizada utilizando os próprios eventos fisiológicos, onde podem ser comparadas as dosagens obtidas por duas amostras diferentes (p. ex. fezes e urina, dosando metabólitos, ou sangue e saliva, dosando a forma ativa) e comparando padrões de excreção com comportamentos conforme a condição reprodutiva (p. ex. aumento de estrogênio com comportamento de cópula; gestação e aumento de progesterona circulante, seguida do parto com queda na progesterona) (Brown, 2008).

Também pode ser realizada por meio de desafio hormonal, quando é administrado um fármaco que, conhecidamente, estimule a produção hormonal. Além de demonstrar o tempo de excreção após o estímulo da glândula, podemos acompanhar a quantidade de metabólitos excretados pela formação de uma curva, depois de realizadas coletas sucessivas em tempo definido (Fig. 1) (Brown, 2008; Lovas, Johnston e Filippich, 2010).

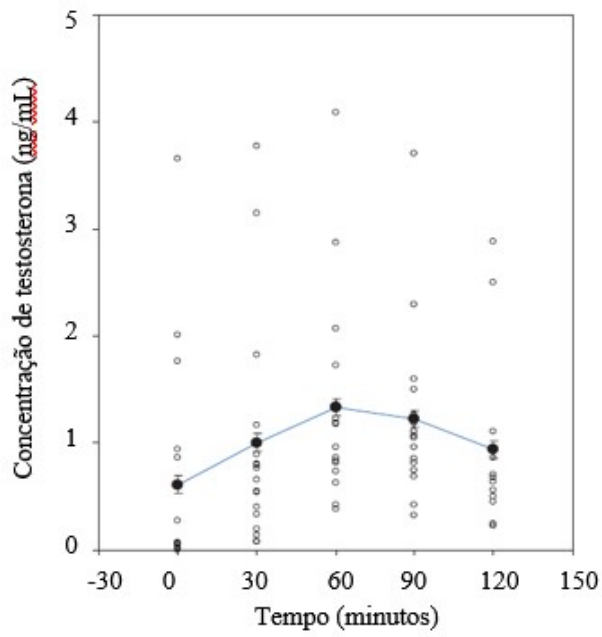

Figura 1. Alterações em concentração de plasma de calopsitas após a injeção de agonista de GnRH, para a validação de ensaio enzimático para testosterona. Podemos observar a curva de excreção, e o pico que se deu em 60 minutos, seguido de um decréscimo. Fonte: Extraído e adaptado de Lovas et al. (2010). 
O teste de paralelismo é uma forma de determinar se o ensaio estar dosando o que deveria efetivamente ser dosado, e também indica a diluição da amostra que deve ser usada no teste. Neste teste, é utilizada uma solução padrão, onde temos uma concentração conhecida do hormônio que teve ser dosado, e a amostra que será dosada. É realizada uma diluição seriada em ambas as soluções, $(1: 1,1: 2,1: 4,1: 8$, $1: 16,1: 32$...) e a dosagem é realizada em todas as diluições. As curvas obtidas devem ser paralelas, ou seja, a dosagem da amostra é imunologicamente similar ao padrão, e pode ser dosada proporcionalmente (Fig. 2) (Brown, 2008).

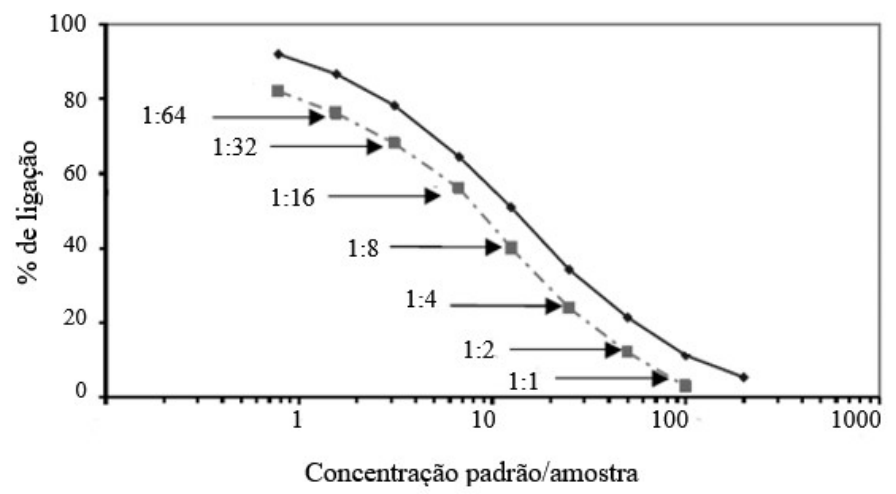

Figura 2. Curva de paralelismo. Dosagem das diluições seriadas (1:1 a 1:64) da solução padrão - concentração do hormônio conhecida (linha sólida) - e da amostra na qual os hormônios estão presentes (linha pontilhada). Ambas as curvas devem ser paralelas, mostrando que a dosagem obtida nas amostras é imunologicamente similar ao padrão. Fonte: Retirado e adaptado de Brown (2008).

\section{Extração}

Antes das análises, os metabólitos de esteroides devem ser extraídos das fezes, pois eles são formados por uma mistura de vários tipos de metabólitos, com diferentes polaridades. Geralmente é realizada com auxílio de um solvente orgânico, separando os esteroides de outros componentes solúveis em água (Wehner e Handke, 1979), aproveitando a característica lipofílica que os hormônios apresentam (Cunningham e Klein, 2007).

Deve-se preferir manter a extração o mais simples possível, apenas ser mais sofisticada caso a concentração seja muito baixa na amostra (Palme, 2005). Estas técnicas também devem ser validadas para cada espécie, e até para cada sexo (Touma e Palme, 2005).

Os esteroides são metabolizados no fígado, inclusive progesterona e testosterona, e a presença dos hormônios não metabolizados nas fezes é praticamente nula (Möstl e Palme, 2002).

\section{Dosagem hormonal}

\section{Ensaios imunológicos}

Com a habilidade de criar anticorpos específicos contra esteroides e peptídeos, surgiram os ensaios imunológicos, o primeiro a surgir foi o radioimunoensaio (RIA) (Pukazhenthi e Wildt, 2004). As técnicas imunológicas são capazes de detectar pequenas quantidades de hormônios nas amostras (Brown, 2008). Os padrões hormonais durante um certo período puderam ser definidos depois do desenvolvimento da coleta de amostras sanguíneas sequenciais, mas essa prática não é segura ou viável para ser realizada em todas as espécies (Pukazhenthi e Wildt, 2004). Os ensaios imunológicos são os mais usados quando empregamos amostras como urina, fezes ou excretas (Palme, 2005), porém, técnicas de cromatografia estão começando a ser utilizadas e aprimoradas para o uso com coletas não invasivas (Spercoski, 2019, UFPR - comunicação pessoal).

\section{Radioimunoensaio (RIA)}

Os ensaios utilizando marcadores radioativos são altamente sensíveis e eram os mais comuns, mas acabam por ser mais complicados, por necessitar de licença especial para o uso de radioisótopos e pelos equipamentos de detecção serem de alto valor (Brown, 2008). 
Os RIA's dependem da ligação do antígeno à uma molécula radioativa, geralmente iodo-125 ou hidrogênio-3 (trítio), que serve como o rastreador. A competição de ligação acontece entre o antígeno não marcado, presente na amostra (hormônio na amostra) e uma substância estruturalmente parecida com o antígeno da amostra, porém, marcado com a molécula reativa (Brown, 2008). Ambos os antígenos competem pela ligação com o anticorpo que foi desenvolvido especificamente contra o hormônio.

A leitura do ensaio é realizada em um contador de cintilação beta ou gama. O resultado geralmente é inversamente proporcional ao que buscamos, pois teremos a leitura da ligação entre anticorpo e antígeno marcado, e não o antígeno da amostra.

\section{Enzimoimunoensaio (EIA)}

Comparados aos RIA's, os ensaios enzimáticos, também conhecidos como ELISA (Enzyme Linked Immunosorbent Assay, ensaio de imunoabsorção enzimática), apresentam algumas vantagens, como: não utilizar radioatividade; equipamentos de custo mais baixo e reagentes de simples preparo, estáveis e com maior validade. Atualmente, os EIA's já são tão sensíveis quanto os RIA's, e estão ganhando popularidade (Brown, 2008; Wild, 2013).

O EIA baseia-se na ligação entre um antígeno e uma enzima, mantendo tanto as atividades enzimáticas quanto imunológicas no conjugado (antígeno marcado). Geralmente esse conjugado é um hormônio ligado a uma peroxidase de raiz forte (HRP, do inglês, horseradish peroxidase), que serve como rastreador. Esse hormônio, conjugado com a enzima, compete com o hormônio presente na amostra (antígeno na amostra) pela ligação com o anticorpo, que foi desenvolvido especificamente contra o hormônio (Brown, 2008).

A reação de revelação ocorre após certo tempo de incubação, que depende do protocolo que é utilizado. Como haverá a ligação entre o anticorpo aos dois antígenos presentes na solução, adiciona-se o substrato da enzima, que se liga a ela e causa a alteração de cor. Quando a enzima utilizada é o HRP, podem ser usados os substratos ABTS (ácido 2,2'-azino-bis(3-etilbenzotiazolina-6-sulfônico)) que gera cor verde, ou o TMB (tetrametil-benzidina) que gera uma coloração azul (Brown, 2008; Wild, 2013).

A reação colorimétrica é inversamente proporcional ao resultado procurado: quanto mais intensa a cor, menor a quantidade de hormônio presente naquela amostra, pois o conjugado que promove a formação de cor é o hormônio sintético marcado (Brown, 2008; Wild, 2013). A leitura é feita por espectrofotometria, para estimar a intensidade da coloração e assim a concentração do que está sendo analisado (Wild, 2013).

\section{Considerações finais}

Técnicas de dosagem hormonal não invasivas estão sendo cada vez mais exploradas na área de endocrinologia animal. Com a conscientização do estresse causado pela manipulação do animal e os riscos anestésicos, as técnicas vêm sendo validadas para várias espécies e, na maioria dos casos, são têm sido utilizadas com sucesso.

Com o aumento do quantitativo de trabalhos com reprodução assistida em animais silvestres, tanto para populações em cativeiro quanto para recolocação da espécie quando extintas localmente, tornase cada vez mais importante o conhecimento dos ciclos hormonais ligados à reprodução, assim como o conhecimento de como estes podem ser afetados.

Do exposto, ressalta-se, a o quão tem sido importante o processo de modernização das técnicas e de trabalhos com amostras que diminuem o contato com o animal, que mesmo apresentando algumas limitações, trazem muito bons resultados para as pesquisas e trabalhos de conservação e, certamente, continuará crescendo, à medida em que se desenvolve a endocrinologia como ciência e os pesquisadores tornam-se mais conscientes de sua função de produzir ciência.

\section{Referências}

Almeida ACD, Moreira N. Influência do enriquecimento ambiental em araras-canindé (Ara ararauna). Dissertação de Mestrado. Universidade Federal do Paraná, 2016.

Brown J. Wildlife Endocrinology Manual. Smithsonian National Zoological Park, Conservation and Research Center (Publicação interna), 2008.

Cunningham JG, Klein BG. Veterinary physiology. Missouri: Saunders Elsevier, 2007.

Blank MH, Moreira N. Perfil anual de andrógenos em gaviões-reais (Harpia harpyja) e sua correlação 
com comportamento reprodutivo e fatores ambientais. Dissertação de Mestrado. Universidade Federal do Paraná, 2015.

Buchanan KL, Goldsmith AR. Noninvasive endocrine data for behavioural studies: the importance of validation. Anim Behav, v.67, n.1, p.183-185, 2004.

Ferreira JCP, Fujihara CJ, Fruhvald E, Trevisol E, Destro FC, Teixeira CR, Pantoja JCF, Schmidt SEM, Palme R. Non-invasive measurement of adrenocortical activity in blue-fronted parrots (Amazona aestiva, Linnaeus, 1758). PloS one, v.10, n.12, 2015.

Goymann W. Noninvasive monitoring of hormones in bird droppings: physiological validation, sampling, extraction, sex differences, and the influence of diet on hormone metabolite levels. Ann. N. Y. Acad Sci, v.1046, n.1, p.35-53, 1 jun. 2005b.

Goymann W. On the use of non-invasive hormone research in uncontrolled, natural environments: the problem with sex, diet, metabolic rate and the individual. Methods Ecol Evol, v.3, n.4, p.757-765, 2012.

Gratto-Trevor CL, Oring LW, Fivizzani AJ. Effects of blood sampling stress on hormone levels in the semipalmated sandpiper. J. Field Ornithol, v.62, n.1, p.19-27, 1991.

Heistermann M. Non-invasive monitoring of endocrine status in laboratory primates: methods, guidelines and applications. Sci Adv, v.5, n.1, p.1-9, 2010.

Hodges K, Brown J, Heistermann M. Endocrine monitoring of reproduction and stress. In: Kleiman, D. G.; Thompson, K. V.; C. Baer, K. (Eds.). Wild mammals in captivity: Principles and techniques for zoo management. 2. ed. Chicago, IL: University of Chicago Press, p.447-468, 2010.

Klasing KC. Potential Impact of Nutritional Strategy on Noninvasive Measurements of Hormones in Birds. Ann. N. Y. Acad Sci, v.1046, n.1, p.5-16, 2005.

Lovas E, Johnston S, Filippich L. Using a GnRH agonist to obtain an index of testosterone secretory capacity in the cockatiel (Nymphicus hollandicus) and sulphur-crested cockatoo (Cacatua galerita). Aust. Vet J, v.88, n.1-2, p.52-56, 2010.

Möstl E, Palme R. Hormones as indicators of stress. Domest. Anim Endocrinol, v.23, p.64-74, 2002.

Möstl E, Rettenbacher S, Palme R. Measurement of corticosterone metabolites in birds' droppings: An analytical approach. Ann. N. Y. Acad Sci, v.1046, p.17-34, 2005.

Palme R. Measuring fecal steroids: Guidelines for practical application. Ann. N. Y. Acad Sci, v.1046, p.75-80, 2005.

Pukazhenthi BS, Wildt DE. Which reproductive technologies are most relevant to studying, managing and conserving wildlife? Reprod. Fertil Dev, v.16, n.2, p.33-46, 2004.

Scanes CG. Sturkie's Avian Physiology. 6 ed. Elsevier, 2015.

Schwarzenberger F. The many uses of non-invasive faecal steroid monitoring in zoo and wildlife species. Int Zoo Yearb, v.41, n.1, p.52-74, 2007.

Taylor W. The excretion of steroid hormone metabolites in bile and feces. Vitam. Horm, Academic Press, v.29, 1971.

Touma C, Palme R. Measuring fecal glucocorticoid metabolites in mammals and birds: The importance of validation. Ann. N. Y. Acad Sci, v.1046, p.54-74, 2005.

Wasser SK, Hunt KE, Brown JL, Cooper K, Crockett CM, Bechert U, Millspaugh JJ, Larson S; Monfort SL. A generalized fecal glucocorticoid assay for use in a diverse array of nondomestic mammalian and avian species. Gen Comp Endocrinol, v.120, n.3, p.260-275, 2000.

Wasser SK, Hunt KE. Noninvasive measures of reproductive function and disturbance in the barred owl, great horned owl, and northern spotted owl. Ann. N. Y. Acad Sci, v.1046, n.2005, p.109-137, 2005.

Wehner R, Handke A. An improved extraction method for plasma steroid hormones. Clin Chim Acta, v.93, p.429-431, 1979.

Wild D. The Immunoassay Handbook. Theory and Applications of Ligand Binding, ELISA and Related Techniques. 4 ed. Elsevier, 2013. 